\title{
Preparation and Properties of Nanocomposite Coatings by Pulsed Current-Jet Electrodeposition
}

\author{
Kailin Zhao ${ }^{1}$, Lida Shen ${ }^{1, *}$, Mingbo Qiu, Zongjun Tian, Wei Jiang \\ College of Mechanical and Electrical Engineering, Nanjing University of Aeronautics and \\ Astronautics, No. 29 Yudao Street, Nanjing, Jiangsu 210016, PR China. \\ ${ }^{1}$ These authors contributed equally to this work. \\ *E-mail: $\underline{\text { ldshen@nuaa.edu.cn }}$
}

doi: $10.20964 / 2017.09 .04$

Received: 24 May 2017 / Accepted: 29 June 2017 / Published: 13 August 2017

To improve the surface quality and properties of nanocomposite coatings, a method using pulsed current-jet electrodeposition was adopted to prepare $\mathrm{Ni}-\mathrm{Al}_{2} \mathrm{O}_{3}$ nanocomposite coatings. The effects of nanoparticle concentration and pulse current on the surface morphology, grain size and performance of the coatings were examined. The surface morphology of the coatings and the distribution of nanoparticles were analyzed by scanning electron microscopy. The microstructure and grain size of the coatings were studied by X-ray diffractometer. The microhardness and corrosion resistance of the coatings were characterized by microhardness tester and electrochemical workstation, respectively. The results showed that, adding proper amount of nano- $\mathrm{Al}_{2} \mathrm{O}_{3}$ in plating solution can improve the microhardness and corrosion resistance of the coatings. The coatings prepared by pulsed current-jet electrodeposition possessed smoother surface morphology, finer grain size and better dispersion of nanoparticles compared with the coatings prepared by direct current-jet electrodeposition. The former exhibited higher microhardness and better corrosion resistance compared with the latter.

Keywords: jet electrodeposition; pulse current; nanocomposite coatings; microhardness; corrosion resistance

\section{FULL TEXT}

(C) 2017 The Authors. Published by ESG (www.electrochemsci.org). This article is an open access article distributed under the terms and conditions of the Creative Commons Attribution license (http://creativecommons.org/licenses/by/4.0/). 